\title{
Objective assessment of antianginal treatment: a double-blind comparison of propranolol, nifedipine, and their combination
}

\section{Summary and conclusions}

In a double-blind clinical trial the antianginal effects of nifedipine (30 and $60 \mathrm{mg} / \mathrm{day}$ ) and propranolol (240 and $480 \mathrm{mg} /$ day) and a combination of both drugs were compared with those of placebo in 16 patients with severe exertional angina pectoris. Response to treatment was assessed by the objective criteria of 16-point precordial exercise mapping and 48-hour ambulatory electrocardiographic monitoring and subjectively by analysis of patients' daily diaries of episodes of angina and consumption of glyceryl trinitrate. The incidence of pain and consumption of glyceryl trinitrate were significantly decreased by each drug compared with placebo, and the combination produced a further significant improvement. Objectively, the total area and amount of ST depression on the precordial exercise map and the total number of episodes of ST depression detected on ambulatory monitoring confirmed the efficacy of each treatment regimen; the combination was significantly better than either drug alone $(p<0.005)$.

The objective methods permitted greater separation of treatment efficacy and showed reliably that the combination of propranolol and nifedipine was significantly better than either drug alone. Thus this combination is a safe and effective form of treatment for angina.

\section{Introduction}

Although beta-adrenoceptor-blocking agents are well established in the management of patients with angina pectoris, not all patients respond adequately even to large doses. In addition, some patients are troubled by their side effects and in a few relative contraindications exist including heart failure, electrocardiographic conduction abnormalities, and a history of asthma. When such problems arise an alternative form of treatment is needed.

The use of calcium antagonists, notably verapamil, has been assessed in the management of exertional and variant angina, ${ }^{1-3}$ but objective measurement of their effects as well as those of beta-adrenoceptor-blocking agents is desirable. Calcium antagonists inhibit transmembrane calcium influx, which is necessary for cardiac and smooth-muscle contraction. In-vitro studies showed that nifedipine, a potent calcium antagonist, is relatively selective for vascular smooth muscle including the coronary arteries. ${ }^{4}$ This suggested that nifedipine might have beneficial antianginal properties, and it has proved effective ${ }^{5}$ especially in variant angina. ${ }^{6}$ Moreover, electrophysiological studies showed that nifedipine has no direct effect on atrioventricular conduction or sinus node activity, ${ }^{7}$ so that it may be safely combined with

Division of Cardiovascular Disease, Royal Postgraduate Medical School, Hammersmith Hospital, London W12

PETER LYNCH, MB, research fellow and honorary registrar (present address: Prince Henry Hospital, Melbourne, Australia)

HENRY DARGIE, MB, MRCP, honorary senior registrar

SHIRLEY KRIKLER, research assistant

DENNIS KRIKLER, MD, FRCP, consultant cardiologist beta-blocking agents. Since transmembrane calcium influx is facilitated by beta-adrenoceptor stimulation the combination of beta-blockade and calcium antagonism might result in a useful drug interaction. We undertook the present study to assess the relative efficacy of each type of drug when given alone and in combination to patients with severe angina pectoris in a controlled clinical trial.

\section{Patients and methods}

Patients were recruited on the basis of a clinical history of angina pectoris with at least one attack a day despite medical treatment usually comprising beta-adrenoceptor-blocking agents and nitrates. Angina due to coronary artery disease was diagnosed after exclusion of secondary causes by appropriate clinical, biochemical, radiological, and electrocardiographic screening. Other reasons for exclusion were the presence of obstructive airways disease, pronounced conduction abnormalities on the electrocardiogram, a history of heart failure, or the occurrence of myocardial infarction within the previous three months. Formal entry to the trial took place if after a two-week run-in period when the patients took the placebo (all other treatments having been withdrawn) the exercise test was unequivocally positive using the technique of 16-point precordial ST-segment mapping. ${ }^{8}$

We studied 16 patients (14 men and two women), whose mean age was $57 \cdot 7$ years (range $42-71$ years). Thirteen patients had a fully documented history of myocardial infarction and two had only electrocardiographic evidence of previous infarction. Of 15 patients who had been heavy cigarette smokers (20-30 cigarettes/day), all but two had stopped smoking before the trial, and their smoking habits did not change during the trial. The mean duration of angina was 6.2 years (range 1-17 years), and all 16 patients had "stable" angina-that is, the pattern of their angina had not changed for at least six months before they entered the study.

\section{TRIAL DESIGN}

The trial was conducted double blind, and a "double-dummy" technique was used so that at all times the treatment was visually identical. There were four treatment periods of four weeks each, the treatments comprising propranolol, nifedipine, propranolol and nifedipine combined, and placebo; during the first two weeks of each active period the dosages used were propranolol $80 \mathrm{mg}$ thrice daily and nifedipine $10 \mathrm{mg}$ thrice daily, while the last two weeks were at the higher doses of $160 \mathrm{mg}$ and $20 \mathrm{mg}$ respectively thrice daily. All patients received all treatments, the order of administration being determined by a balanced latin square. All drugs were dispensed by the same pharmacist, who kept the treatment code and checked patient compliance by tablet counting every two weeks.

\section{SUBJECTIVE ASSESSMENT}

Incidence of angina and consumption of glyceryl trinitrate-Patients were encouraged to follow their normal daily routine throughout the period of the trial. They were discouraged from using glyceryl trinitrate prophylactically, though they were told to use it when necessary for attacks of angina. Each patient kept a diary, which was divided into four periods corresponding to morning, afternoon, evening, and night; they recorded attacks, whether they took glyceryl trinitrate (and how many tablets), and what they were doing just before the attack.

Side effects-At the end of each treatment period patients completed, at home, a questionnaire on side effects. 


\section{OBJECTIVE ASSESSMENTS}

Exercise testing-Exercise was performed on an electronically braked bicycle ergometer beginning at $50 \mathrm{~W}$ and progressively increasing the work load, the end point of the test being severe dyspnoea or chest pain, intolerable fatigue, or important arrhythmia. Systolic blood pressure and heart rate were recorded before and at each minute during exercise, and precordial maps were recorded before and immediately after and at one, three, five, and 10 minutes after exercise. Exercise tests were carried out at the end of the placebo run-in period and at two-weekly intervals during the trial. During each treatment period patients were exercised to the same work load as that achieved during the placebo run-in period. The exercise maps were analysed by counting the number of positions showing significant ST depression $(\geqslant 1 \mathrm{~mm}$ ) at each recording made after exercise (thereafter termed the area of ischaemia) and by summing the number of millimetres of ST depression at all these points. The product of systolic blood pressure and heart rate (double product) was calculated at peak exercise as an index of myocardial oxygen demand. ${ }^{9}$

Ambulatory monitoring-During the 48 hours before each exercise test patients were assessed by ambulatory electrocardiographic monitoring. Scrupulous attention was paid to skin preparation and electrode placement, the monitoring electrode being sited at the point of maximum ST-segment depression recorded during the exercise test. An Oxford Medilog 1 recorder was used, and the tapes were read visually on a Reynolds Pathfinder analyser by an observer unaware of the treatment received; we counted all episodes of ST-segment depression of $1 \mathrm{~mm}$ or more.

\section{Results}

\section{SUBJECTIVE DATA}

The incidence of anginal pain and consumption of glyceryl trinitrate were significantly decreased with both drugs compared with placebo (figs 1 and 2), but propranolol produced significantly greater reductions than nifedipine in both variables $(p<0.005$ and $p<0.01$ respectively). While the higher dose of propranolol conferred no additional benefit over the lower dose, nifedipine $60 \mathrm{mg} /$ day was significantly more effective than nifedipine $30 \mathrm{mg} /$ day in reducing the incidence of pain and consumption of glyceryl trinitrate $(p<0.005$ and $\mathrm{p}<0.025$ respectively). The higher dose of the combination reduced these two variables further $(p<0.01)$.

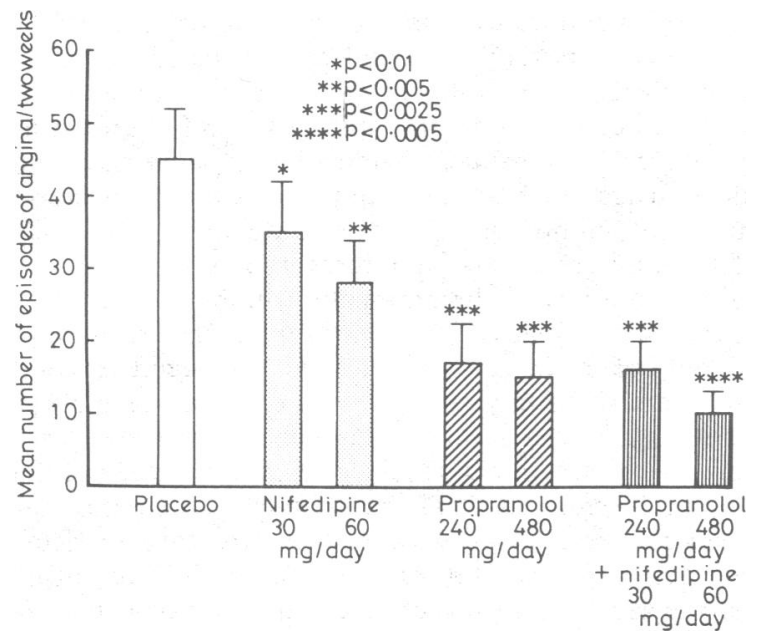

FIG 1-Incidence of anginal pain. Values are mean $\pm S E M$ numbers of attacks during each two-week period.

\section{OBJECTIVE DATA}

Exercise precordial mapping-Figure 3 shows that both drugs significantly reduced the area of ST-segment change when compared with placebo but that the higher dose of propranolol was no more effective than the lower dose. The effect of propranolol was greater than that of nifedipine $(p<0.01)$, while the combination produced further significant reductions $(p<0.01)$. The combination of the higher doses reduced the area of ischaemia on the precordial map by $90 \%$ compared with placebo $(p<0.001)$. Figure 4 shows the product of the maximum exercise-induced heart rate and blood pressure (double product) for each treatment period. The double product was not significantly changed by nifedipine but was significantly reduced by propranolol $(p<0.001)$. The combination was no more effective in reducing the double product than the higher dose of propranolol.

Ambulatory electrocardiographic monitoring-Differences between treatment periods were similar to those seen with the mapping-that is, both drugs alone were significantly better than placebo, and the

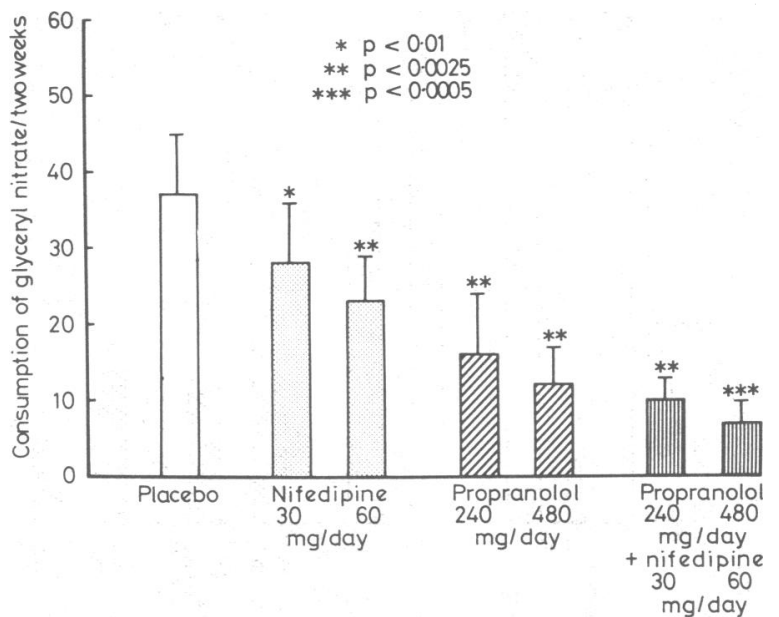

FIG 2-Consumption of glyceryl trinitrate. Values are mean \pm SEM numbers of tablets consumed during each two-week period.

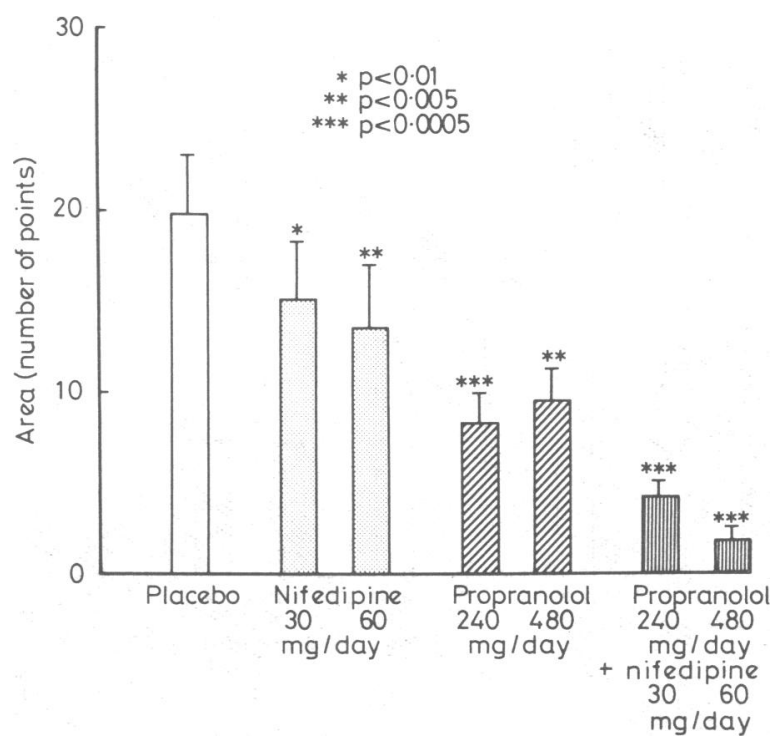

FIG 3-Mean \pm SEM areas of exercise-induced ST-segment depression.

combination of drugs produced further significant improvement compared with either drug alone (fig 5). Furthermore, the higher dose of propranolol was not significantly better than the lower dose, whereas the higher dose of the combination was significantly better than the lower.

In this study $59 \%$ of all episodes of appreciable ST depression were unassociated with symptoms of angina pectoris, but these painless episodes responded similarly within each treatment period to the episodes associated with angina. Propranolol produced highly significant reductions in the mean heart rate measured over 48 hours, from $74 \pm 4$ beats $/ \mathrm{min}$ (placebo) to $58 \pm 3$ beats $/ \mathrm{min}(\mathrm{p}<0.001)$. Neither dose of nifedipine produced any significant changes in the mean ambulatory heart rates over the 48 -hour period $(75 \pm 4$ beats/ $\mathrm{min})$, nor was there any significant change with the combination. 


\section{SIDE EFFECTS AND COMPLIANCE}

The most common side effect when patients took propranolol was coldness or numbness of the fingers (experienced by seven patients when taking propranolol alone and six when taking the combination). With nifedipine the commonest side effect was swelling of the ankles (eight patients). Headache occurred to the same extent in all treatment periods and affected five of the patients. In general the side effects were mild, and only one patient dropped out. Compliance with treatment as estimated by tablet counting was $95 \%$.

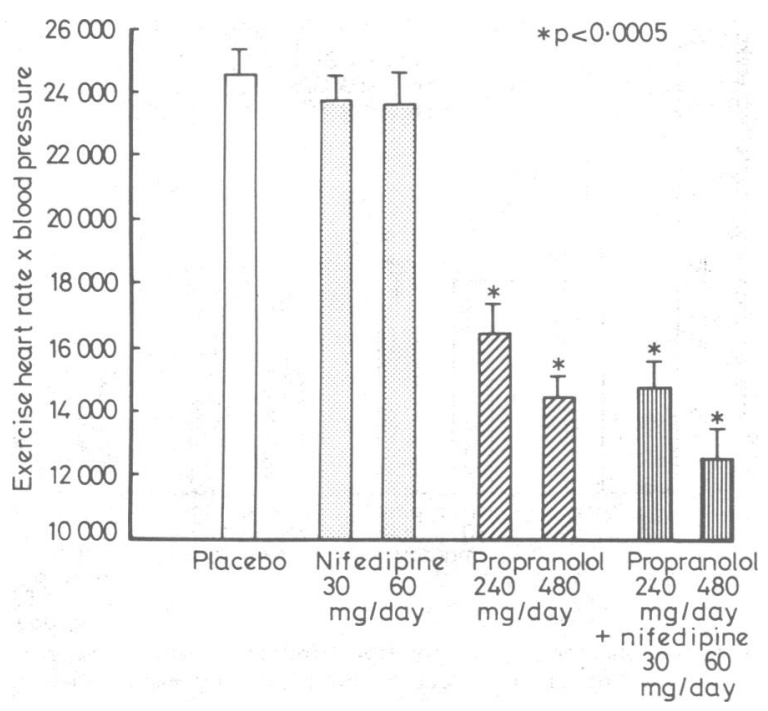

FIG 4-Mean \pm SEM double products at peak exercise heart rate.

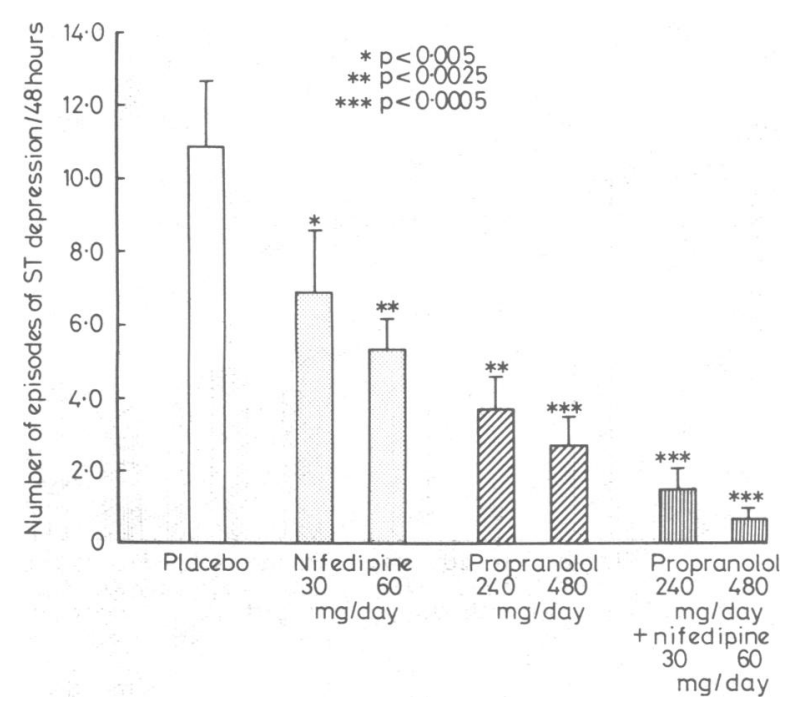

FIG 5-Mean \pm SEM numbers of episodes of ST-segment depression during 48-hour monitoring period.

\section{Discussion}

The patients in this clinical trial were recruited because they continued to have at least one attack of angina a day despite treatment with beta-adrenoceptor-blocking agents and nitrates; none had angina at rest. Their exercise precordial maps during the placebo run-in period suggested that they had triple-vessel disease. ${ }^{10}$ The incomplete response to beta-adrenoceptor blockade therefore reflected the severity of their coronary artery disease rather than an underlying mechanism unresponsive to beta-blockade such as coronary spasm. ${ }^{11}$ That they were partially responsive to beta-blockade is indicated by the magnitude of the improvement shown by the subjective and objective assessments during each treatment period compared with the placebo period. Interestingly, the lower dose of propranolol ( $240 \mathrm{mg} /$ day) was as effective as the higher dose $(480 \mathrm{mg} /$ day $)$. Nifedipine also produced considerable subjective and objective improvement in angina, though this was less than that with propranolol, and $60 \mathrm{mg} /$ day was clearly better than $30 \mathrm{mg} /$ day. The most noteworthy finding was the conspicuous beneficial effect of the combination of nifedipine and propranolol, as shown by the objective assessments of precordial exercise mapping and ambulatory electrocardiographic monitoring. The higher combination dose caused the area of exercise-induced ST-segment depression and the number of ambulatory episodes of STsegment depression to fall by 90 and $95 \%$ respectively compared with placebo $(\mathrm{p}<0.001)$.

Both doses of propranolol reduced exercise tachycardia by about $30 \%$, with no significant difference between the two doses, and this, together with a small reduction in exercise systolic blood pressure, resulted in an important decrease in the exercise double product $(40 \%)$. These haemodynamic changes reflecting a conspicuous reduction in myocardial oxygen demand would adequately explain the associated beneficial effects of propranolol on the area and severity of ST-segment depression recorded in this study. On the other hand, the beneficial effects of nifedipine on the precordial map were not accompanied by any significant changes in exercise double product. Furthermore, the pronounced improvement in the exercise precordial map that occurred with the combination when compared with propranolol alone was achieved without any further significant alteration in the exercise double product. Thus a mechanism other than reduction in myocardial oxygen demand must have been responsible, and in view of the known actions of nifedipine ${ }^{12}$ an increase in coronary blood flow cannot be excluded.

The effects of the various treatments as shown by ambulatory monitoring closely reflected the changes on the precordial exercise maps. Indeed, this might have been expected, since the exploring electrode was positioned at the site of the maximum exercise-induced ST-segment depression recorded on the precordial map. About $60 \%$ of all episodes of appreciable STsegment depression detected by ambulatory monitoring were painless. This is slightly lower than has been found in other series $^{1314}$ but was observed in over 6000 hours of recording. In general the painless episodes lasted longer than the painful ones but glyceryl trinitrate was taken during the painful ones. There was no indication that the painless and painful episodes responded particularly differently to the various treatment regimens. Painless and painful episodes of ST-segment depression represent myocardial ischaemia in the same way, ${ }^{15}$ and the effects of drugs on their frequency and severity are important.

The double-blind nature of this study and of the analysis of the data eliminated bias in interpreting the results. This is crucial with respect to the ambulatory monitoring tapes, which were analysed visually. The validity of the non-frequencymodulated Oxford Medilog 1 system for ST-segment monitoring is controversial. ${ }^{16}$ Only unequivocal episodes of ST-segment depression (1 mm or more) were analysed, the observer being unaware of the treatment received. Any technical problems in recording ST segments would not influence one period more or less than another. Thus with proper attention to detail and suitable design of the clinical trial this method of ambulatory monitoring seems to be a valid and important objective method of assessing response to treatment.

This study has shown an important beneficial drug interaction between a beta-blocker and a calcium antagonist. Both have known antianginal actions, but together they produce appreciable subjective and objective improvement with good tolerance.

HD was supported by the British Heart Foundation, and PL by Bayer UK.

Requests for reprints should be addressed to Dr H Dargie, Cardiovascular Research Unit, Royal Postgraduate Medical School, London W12 0HS. 


\section{References}

${ }^{1}$ De Ponti C, Mauri F, Ciliberto GR, Caru B. Comparative effects of nifedipine, verapamil, isosorbide dinitrate and propranolol on exercise induced angina pectoris. Eur 7 Cardiol 1979;10:47-58.

2 Livesley B, Catley PF, Campbell RC, Oram S. Double-blind evaluation of verapamil, propranolol, and isosorbide dinitrate against a placebo in the treatment of angina pectoris. $\mathrm{Br} \mathrm{Med} \mathcal{F} 1973 ; \mathrm{i}: 375-8$.

${ }^{3}$ Parodi O, Maseri A, Simonetti I. Management of unstable angina at rest by verapamil: a double-blind cross-over study in coronary care unit. Br Heart 7 1979;41:167-74.

4 Fleckenstein A. Specific inhibitors and promoters of calcium action in the excitation contraction coupling of heart muscle and their role in the prevention or production of myocardial lesions. In: Harris P, Opie L, eds. Calcium and the heart. London: Academic Press, 1970: 135-86.

5 Ekelund LG, Oro L. Antianginal efficiency of nifedipine with and without a beta blocker studied with exercise test. A double-blind randomised subacute study. Clin Cardiol 1979;2:203-11.

- Muller JE, Gunther SJ. Nifedipine therapy for Prinzmetal's angina. Circulation 1979;57:137-9.

${ }^{7}$ Rowland E, Evans T, Krikler D. Effect of nifedipine on atrioventricular conduction as compared with verapamil. Br Heart $\mathcal{f} 1979$;42:124-7.

${ }^{8}$ Fox K, Selwyn A, Shillingford JP. A method for praecordial surface mapping of the exercise electrocardiogram. Br Heart $71978 ; 40: 1339-43$.
9 Katz LN, Feinberg $H$. The relation of cardiac effort to myocardial oxygen consumption and coronary flow. Circ Res 1958;6:656-69.

${ }^{10}$ Fox KM, Selwyn A, Oakley D, Shillingford JP. Relation between the precordial projection of ST segment changes after exercise and coronary angiographic findings. Am $\mathcal{f}$ Cardiol 1979;44:1068-75.

11 Hillis LD, Braunwald E. Coronary artery spasm. New Engl f Med 1978; 299:695-702.

12 Vater W. Myocardial oxygen consumption under the influence of nifedipine (Adalat) in the anesthetized dog. In : Lochner W, Braasch W, Kroneberg $\mathrm{G}$, eds. Second international nifedipine (Adalat) symposium. New York: Springer-Verlag, 1975:77-81.

${ }^{13}$ Schang SJ, Pepine CJ. Transient asymptomatic ST segment depression during daily activity. Am $\mathcal{F}$ Cardiol $1977 ; 39: 396-402$.

14 Selwyn AP, Fox K, Eves M, Oakley D, Dargie HJ, Shillingford J. Myocardial ischaemia in patients with frequent angina pectoris. $\mathrm{Br} \mathrm{Med} \mathcal{F}$ 1978 ;ii:1594-6.

${ }^{15}$ Maseri A, Silva S, de Nes M, L'Abbate A, Chierchia S. "Variant angina": one aspect of a continuous spectrum of vasospastic myocardial ischemia. Am f Cardiol 1978;42:1019-35.

16 Balasubramanian V, Raftery EB, Stott FD. Myocardial ischaemia in patients with frequent angina pectoris. $B r \operatorname{Med} \mathcal{f} 1979 ; \mathrm{i}: 198$.

(Accepted 16 May 1980)

\title{
Outbreak of tuberculosis after minimal exposure to infection
}

\author{
V R RAO， R F JOANES，PAULA KILBANE， N S GALBRAITH
}

\section{Summary and conclusions}

The identification of a case of respiratory tuberculosis in a swimming-baths attendant whose sputum was smear positive was followed by intensive contact tracing of children aged 8-11 years who had visited the baths. An outbreak was discovered that otherwise might not have been detected. Out of 3764 children, $108(2.9 \%)$ had evidence of infection: there were 16 cases of tuberculosis, of which 11 were symptomless but showed lesions on chest radiography, and a further 92 with tine test grade 3 or 4 without clinical or radiological signs. The contact of these children with the index case was apparently minimal.

Early detection, isolation, and treatment of infectious cases of respiratory tuberculosis and vigorous contact tracing should be given more priority in tuberculosis control.

\section{Introduction}

An outbreak of tuberculosis in children aged 8-11 years occurred between January and March 1979 in Sandwell, West Midlands, a metropolitan district with a matching single-district area health authority, situated immediately north-west of Birmingham. It is a heavy industrial district with a declining population, which at the 1971 Census numbered 328100 , over $3 \%$ of whom were Asian immigrants. Infant and perinatal

\footnotetext{
Sandwell Area Health Authority, West Bromwich, West Midlands B70 9OD

V R RAO, MFCM, DPH, specialist in community medicine (environmental health)

R F JOANES, MFCM, DPH, specialist in community medicine (child health)

Communicable Disease Surveillance Centre, London NW9 5EQ PAULA KILBANE, MFCM, senior registrar N S GALBRAITH, MRCP, FFCM, director
}

mortality rates exceeded the national average. The notification rate of tuberculosis in 1977 was over twice the national rate, which possibly reflected the problem of tuberculosis in innercity immigrants experienced elsewhere in Britain. ${ }^{2}$ This part of the West Midlands was well provided with tuberculosis services; there were three chest clinics, with attached healthvisiting staff, each of which served part of the Sandwell area.

The outbreak was detected by intensive contact tracing of children who had used a swimming pool supervised by a man with the disease.

\section{Index case}

The index case was a 25-year-old United-Kingdom born white man who had worked for Sandwell Borough Council as a baths attendant since November 1976. A pre-employment chest radiograph had been normal. He began to feel unwell in the spring of 1978, developed a cough in the summer, which he attributed to his heavy smoking (40 cigarettes a day) and in the autumn became breathless on exertion, tired, and lost his appetite. He had a haemoptysis at work in February 1979 and was referred to the local chest clinic. Radiography showed extensive bilateral tuberculosis, and a sputum-smear test was positive. He was admitted to hospital for isolation and treatment. He recalled that in August 1978 he had undergone chest radiography after a minor motorbike accident; the radiograph showed a small right middle-lobe cavity, which had escaped detection at the time. The source of his infection was not discovered.

His work as an attendant at a local heated indoor swimming pool entailed keeping the surrounds of the pool clean and free of obstruction and supervising bathers. Supervision was carried out sitting on a $6 \mathrm{ft}$ $(1.8 \mathrm{~m})$ high platform in the centre of one side of the pool, from which bathers could readily be observed in any part of the pool. He never instructed in swimming or life saving and apparently had no close contact with bathers.

\section{Outbreak}

Immediately the index case was detected his close home and work contacts were examined. Out of 13 adults, one (his girlfriend) had a small apical shadow, but the remainder were normal. One child, the 